\title{
A representação simbólica do nojo em tempos de isolamento social
}

\author{
The symbolic representation of disgust during the social isolation
}

\begin{abstract}
Alessandra Carvalho Abrahão Sallum ${ }^{1}$
1 Psicóloga, especialista em psicoterapia psicanalítica, sexualidade humana e neuropsicologia. E-mail: alessandrapsicologa@gmail.com Orcid: http://orcid.org/0000-0002-3148-8235
\end{abstract}

RESUMO: Este artigo se propõe a discutir as formas discrepantes como os indivíduos vêm se comportando no que tange a higiene e os relacionamentos interpessoais, na esfera privada e num contexto mais amplo, público, em tempos de pandemia do Covid-19. As principais questões que impulsionam esta análise emanam das diferentes maneiras como o homem vê o problema do contágio, do sujo, do repulsivo e da morte entre seus círculos mais íntimos, bem como a mudança dessa percepção e do próprio comportamento quando confrontado com estranhos. O principal objetivo aqui é trazer à luz pensamentos tabus que podem direcionar a ação humana, a partir do inconsciente, instância psíquica descrita por Freud. Para isso, teremos as obras "O tabu do corpo" e "O tabu da morte" de José Carlos Rodrigues, como base para a elaboração da discussão, sob o olhar da psicanálise. Em situações de catástrofe, evidencia-se quão precária é a condição humana. A partir de comportamentos rituais, muito presentes nos hábitos de higiene estimulados durante a pandemia, o homem imagina possuir controle sobre os elementos externos e internos, fazendo, contudo uma curiosa diferenciação de aproximação ou distanciamento/nojo, dependendo de quão privada/íntima é a relação dele com os demais. A morte não escapa a esta reflexão, assumindo papéis diversos no ideário social, também trespassada pela natureza das relações existentes.

Palavras chave: Coronavírus, nojo, psicanálise.

ABSTRACT: This article aims to discuss the discrepant ways in which individuals have been behaving with regard to hygiene and interpersonal relationships, in the private sphere and in a broader, public context, in times of Covid-19 pandemic. The main questions that drive this analysis emanate from the different ways in which man sees the problem of contagion, the dirty, the repulsive and the death among his most intimate circles, as well as the change in this perception and in his own behavior when confronted with strangers. The main objective here is to bring to light taboo thoughts that can direct human action, starting from the unconscious, a psychic instance described by Freud. For this, we will have the books "O tabu do corpo" and "O tabu da morte" by José Carlos Rodrigues, as a basis for the elaboration of the discussion, under the perspective of psychoanalysis. In catastrophe situations, it shows how precarious the human condition is. Based on ritual behaviors, very present in the hygiene habits stimulated during the pandemic, man imagines having control over the external and internal elements, making, however, a curious differentiation of approach or distance/disgust, depending on how private/intimate the person is. his relationship with others. Death does not escape this reflection, assuming different roles in the social ideal, also pierced by the nature of existing relationships.

Keywords: Coronavirus, disgust, psychoanalysis

\section{Introdução}

Em 11 de março de 2020 a Organização mundial de Saúde (OMS), constatando o crescente número 
de infectados e mortos pelo SARS-CoV-2 (COVID-19) emitiu um pronunciamento que mudaria os rumos deste ano, impactando a sociedade, economia, trabalho, a mobilidade humana e a relação entre indivíduos e nações. "Profundamente preocupada com os níveis alarmantes de propagação da doença e sua gravidade, e também níveis alarmantes de inação, a OMS determina em sua avaliação que o COVID-19 pode ser caracterizado como uma pandemia" (OMS, 2020). Fronteiras foram fechadas e o estado de quarentena adotado como politica de contenção da propagação do vírus em várias partes do mundo.

Neste sentido, alguns modelos de distanciamento social foram propostos. O modelo mais adotado atualmente, e recomendado pela OMS, é o de isolamento horizontal, em que todos os setores da sociedade mantêm-se distanciados, circulando apenas os serviços essenciais e os cidadãos para abastecerem suas casas. O isolamento vertical, pouco adotado e muito questionado, defende que apenas grupos vulneráveis sejam isolados, apostando que a chamada imunidade de rebanho proteja a população. Em locais de grande contágio, o lockdown (confinamento) foi instituído. Ele é uma medica extrema, para situações de forte ameaça ou colapso do sistema de saúde, e se diferencia dos demais modelos descritos pelo nível de restrição imposto.

Médicos, antropólogos, sociólogos e economistas descreveriam a partir deste prólogo linhas infindáveis tratando das causas e consequências desta pandemia a curto, médio e longo prazo, tentando prever cenários mil. Contudo, o objetivo deste estudo é observar a forma intrigante como os sujeitos têm lidado com os tabus ligados à higiene do corpo, os sentimentos de nojo e repulsa expressos em determinadas circunstâncias e a forma como a psicologia e a psicanálise podem compreender tal fenômeno. Interessa-nos também observar a maneira como a morte e o luto, quando muito presentes na sociedade trazem à tona crenças, rituais, tabus que dão ao homem a ilusão de controle sobre sua condição. As principais questões que impulsionam esta análise emanam das diferentes maneiras como o homem vê o problema do contágio, do sujo, do repulsivo e da morte entre seus círculos mais íntimos, bem como a mudança dessa percepção e do próprio comportamento quando confrontado com estranhos. Desenrolar-se-á, a partir das obras "O tabu do corpo" e "O tabu da morte" de José Carlos Rodrigues, uma análise de base psicanalítica acerca das questões apresentadas, compondo um estudo bibliográfico qualitativo, sem intenção de ditar regras, mas de estabelecer reflexões.

Como, nos diferentes estados de distanciamento social, em comunidade ou individualmente, temos conduzido nossas demandas emocionais? O lockdown confina também partes de nossa identidade e liberta fantasmas com os quais teremos que lidar. O invisível e intangível perigo espreita nossas casas, nossos corpos, maculando tudo que é sagrado e intimo, sacudindo estruturas aparentemente sólidas de pensamento e expondo uma fragilidade que diariamente, conscientes ou não, deixamos de encarar.

\section{O Nojo}

Para haver uma sociedade, é preciso que se estabeleçam princípios norteadores, que a definirão, distinguindo-a da natureza. Entende-se como natureza, tudo aquilo que é universal, que não é peculiar a qualquer conjunto de sujeitos. O natural transcende o campo dos hábitos, do que é ensinado e aprendido por qualquer grupo social. Em contrapartida, constitui a cultura "tudo que é particular a determinada sociedade e depende de suas regras" (RODRIGUES, 2006, 1.325).

Por ser uma construção social, a ideia de natureza varia culturalmente. Assim, essa oposição entre natureza e cultura, na qual as sociedades se firmam para justificar sua própria existência, também varia, dependendo de onde se observa. Há grupos com culturas que entrelaçam aspectos naturais à sua vivência, outros os excluem, vendo-os como primitivos. É na relação entre estes dois aspectos que se abstrai o 
conceito de natureza humana, o qual também é mutável. Comportamentos e crenças tidos como naturais, provavelmente foram aprendidos pelo individuo inserido em seu contexto social e cultural. Durkheim, citado por Rodrigues $(2006,1$. 353), afirma que "o homem que a educação deve realizar em nós não é o homem tal qual a natureza o faz, mas tal qual a sociedade quer que ele seja".

O nojo traz significado a nossas vidas, quando, a partir de sua existência, classificamos como repulsivos vários elementos naturais, a forma como lidamos com nossos corpos, suas excreções, secreções, com sua morte e putrefação. De maneira abstrata, o nojo traz ordem e estrutura à sociedade, visto que frequentemente a cultura recorre a seu poder demarcador de fronteiras para consolidar seus limites e crenças fundamentais.

Miller (1997, p. 25) pondera que estamos habituados a pensar em opostos quando se trata de emoções dentro de nossa mente. Amor está para o ódio, assim como alegria para a tristeza, porém, não temos um oposto pronto para o nojo. "O nojo certamente tem algumas afinidades íntimas com outros sentimentos. $\mathrm{Na}$ fala rotineira, usamos desprezo, repugnância, ódio, horror e até medo, para expressar sentimentos que também podemos exprimir na forma de repulsa ou aversão." (MILLER, 1997, p. 25-26) tradução nossa. O nojo é uma emoção complexa, que, para nossa atual cultura, trabalha a serviço da civilização dos homens. A criança pequena não tem plena noção de que deve repudiar suas excreções naturais, urina, fezes, suor e saliva, como algo sujo, contaminado. É na educação que seus familiares vão orientá-la a ter repulsa e nojo por estes conteúdos, exceto em cenas muito especificas, rituais sociais, como no beijo, no sexo, nos esportes onde se transpira para obter sucesso e vitórias etc.

Este autor trata o nojo como um fenômeno psicológico distinto do medo, pois este seria uma resposta para ameaças ao corpo, enquanto a repulsa (nojo) para ameaças à alma. Nossa bagagem cultural usualmente alude à alma como a essência do ser. Nesse sentido, fantasias acerca de contaminações na alma, equivalentes a contusões no corpo são presentes, assim como contusões corporais são temidas por não se ter certeza que estas também não danifiquem a alma. (MILLER, 1997, p. 26).

A esta ideia, podemos complementar a reflexão de Rodrigues (2006, 1. 390) acerca daquilo que é sagrado ou profano em nossa sociedade, como "duas modalidades de ser no mundo: tudo o que é objeto de interdição é sagrado, ao passo que o profano é aquilo a que estas interdições se aplicam". Para lidar com o sagrado, recorremos a comportamentos rituais, que visam manter a demarcação que rege e interdita a mistura desses dois elementos. Contudo, não há um sem que o outro exista. E o nojo é participante ativo neste policiamento de fronteiras.

O nojo intenso convida o medo a comparecer, pois a contaminação é uma coisa assustadora. O medo sem repulsa nos leva a fugir para a segurança e para uma sensação de alívio, mas a repulsa nos coloca no fardo da limpeza e purificação, um trabalho muito mais intenso e problemático do que a mera fuga, que leva mais tempo e que tememos não ter sido bem sucedida. O medo puro decai muito mais rapidamente do que o repugnante lento, sempre persistente. Temos um nome para repulsa imbuída de medo: horror. (MILLER, 1997, p. 26) Tradução nossa.

O nojo, muitas vezes, pode assumir a forma de horror, como dito, quando misturado ao medo. Em situações de contágio, por exemplo, quando a ameaça é indetectável pelos sentidos, a manifestação do horror é muito real. Temos medo de adoecer, temos nojo do agente infeccioso, tudo isso nos deixaria muito em contato com elementos naturais que nossa cultura não controla efetivamente. Deteriora-se toda a estrutura social diante desta invasão. Distantes da segurança que a cultura e a sociedade rotineiramente promovem, tomados pelo medo de, em ultima instância, encararmos nossa degradação como sujeitos sociais e nossa 
morte física, começamos um processo de ressignificação das relações interpessoais, de nossa subjetividade e da própria sociedade a nossa volta. Apegamo-nos a comportamentos dualistas, ritualísticos, de aproximação e afastamento, aceitação ou nojo, de acordo com o que nosso inconsciente julgar seguro ou não.

A atitude ritual elementar para lidar com o sagrado é impedi-lo de estrar em contato com o profano. O tabu isola esses elementos, implicando necessariamente uma punição para toda transgressão. Dessa forma, quando se teme a punição, há a garantia dos limites que sustentam a coesão da comunidade, afastando natural e social, profano e sagrado.

Tudo que se liga à vida do grupo é sagrado, e a função da atitude ritual, tabu, é a de exprimir e manter a solidariedade do grupo. Em tragédias como as ocorridas no estado de Minas Gerais, após o rompimento das barragens de rejeitos de mineração, inúmeras equipes de voluntários se expuseram ao risco de contaminação e intoxicação para salvar sobreviventes ou recuperar os corpos mortos. Tamanha solidariedade oculta a urgência sentida pelos indivíduos de resgatar a unidade social que foi degradada, solapada junto com as barragens. Aquelas comunidades ruiriam, não fossem os esforços para manter de pé suas estruturas materiais e imateriais. Quando afastamos destas cidades o horror, exatamente nos termos anteriormente descritos, colocamo-lo distante não só dessas comunidades, mas da nossa própria. Entretanto, numa pandemia a solidariedade manifesta por proximidade física torna-se inviável, porém, não menos necessária. "A tragédia é que neste caso a melhor maneira de sermos solidários uns com os outros é isolarmo-nos uns dos outros e nem sequer nos tocarmos" (SANTOS, 2020, p. 47).

O sagrado não se relaciona ao mundo dos homens, ou real, concreto, mas sim ao mundo das normas. Assim sendo, por analogia, as noções ideais de pureza, limpeza, saúde e higiene podem ser compreendidas, numa sociedade que se volta cada vez mais à ciência, como sagradas.

Em primeiro lugar, está presente a ideia de que existe um "caminho da civilização", isto é, um modelo de "aperfeiçoamento moral e material" que teria validade para qualquer "povo", sendo dever dos governantes zelar para que tal caminho fosse mais rapidamente percorrido pela sociedade sob seu domínio. Em segundo lugar, há a afirmação de que um dos requisitos para que uma nação atinja a "grandeza" e a "prosperidade" dos "países mais cultos" seria a solução dos problemas de higiene pública. O resultado dessas duas operações mentais é o processo de configuração dos pressupostos da Higiene como uma ideologia: ou seja, como um conjunto de princípios que, estando destinados a conduzir o país ao "verdadeiro", à "civilização", implicam a despolitização da realidade histórica, a legitimação apriorística das decisões quanto às políticas públicas a serem aplicadas no meio urbano. Esses princípios gerais se traduzem em técnicas específicas, e somente a submissão da política à técnica poderia colocar o Brasil no "caminho da civilização". Em suma, tornava-se possível imaginar que haveria uma fôrma "científica" isto é, "neutra", supostamente acima dos interesses particulares e dos conflitos sociais em geral — de gestão dos problemas da cidade e das diferenças sociais nela existentes. (CHALLOUB, 1996, p. 35).

Uma gestão neutra da ameaça de higiene e saúde publica à qual estamos expostos em nosso país é praticamente impossível, pois há a intrusão de questões politicas, históricas, culturais e inconscientes (subjetivas) que impedem a existência dessa neutralidade. Na prática, esse ideal ficaria apenas no imaginário, na ilusão das promessas politicas e nas crenças populares, A doença, um vírus desconhecido e altamente contagioso, a que estamos expostos assume ares profanos, ameaçando a sacralidade da estrutura social, e todo comportamento de prevenção ocupa posição tabu, ritualística, muito mais do que higienista de fato. Essa tendência não é exclusividade brasileira. Em todo o mundo, dadas as proporções de cada cultura, vemos esses tabus se introduzindo nelas de forma cada vez mais consistente.

O COVID-19 ameaça a estabilidade de nosso grupo social, quando desorganiza nossa zona de conforto. A dinâmica social está comprometida quando não podemos mais ter como seguros os 
comportamentos e relacionamentos antes adotados. Apegamo-nos a crenças difundidas, nem sempre eficazes ou coerentes, numa esperança de preservação ou salvação. Aqui o nojo ganha seu protagonismo. O elemento nojento se comporta de forma quase mágica, assumindo poderes de nos invadir, de forma assustadora, acarretando sentimento de perda de controle. O amigo se torna estranho, não tocamos mais nos conhecidos, temos repulsa daquilo que antes nos inspirava confiança, conforto e que fazíamos com a maior naturalidade. Contudo, essa mudança no padrão de comportamento é de certa forma seletiva, ao passo que vemos aturdidos, que familiares, contrariando todas as recomendações de saúde, confraternizam-se sem a menor cerimônia. Elegemos dentre a massa aqueles que estarão imunes a todos estes males, enquanto rechaçamos os demais.

Ao discutir o caso "O homem dos ratos", Freud (1996) permeia a temática do nojo, quando elabora interpretações acerca das fantasias repugnantes, envolvendo ratos ou excreções corporais, despertadas na mente do paciente, ao se sentir pressionado ou rejeitado de alguma forma. Punha-se obrigado a fazer movimentos de reparação, na tentativa de afastar tais pensamentos de si e de seus objetos de amor, a quem usualmente dirigiam-se tais fantasias. Em outro momento de sua obra, Freud (1996) descreve dentre os sintomas do caso Schreber, que este imaginava estar com os órgãos internos apodrecendo, ou mesmo que já estivesse morto, tomado de intensa paranoia. Nessas duas passagens, o que se extrai é que, quando teme, o homem, para se proteger, pode recorrer aos "poderes mágicos do nojo", como algo que deixa o perigo externo à própria mente, preservando o sujeito. Pode-se analisar também que em varias ocasiões, as fantasias aterrorizantes ou repugnantes voltam-se contra o próprio sujeito ou seus objetos de amor, obrigando-o a realizar um movimento de formação reativa. Laplanche e Pontalis (2001, p. 200-201) explicam que:

Em termos econômicos, a formação reativa é um contra investimento de um elemento consciente, de força igual e de direção oposta ao investimento inconsciente. (...) Na realidade, numa dada formação reativa, podemos descobrir a ação da pulsão contra a qual o sujeito se defende; por um lado, esta irrompe brutalmente, quer em certos momentos, quer em certos setores da atividade do sujeito, e são precisamente estes fracassos flagrantes, contrastando com a rigidez da atitude exigida pelo sujeito, que permitem conferir a determinado traço da personalidade o seu valor sintomático; por outro lado, o próprio exercício da virtude que ostenta, o sujeito, levando os seus atos ate as ultimas consequências, não deixa de satisfazer a pulsão antagônica que acaba por infiltrar-se em todo o sistema defensivo.

Em outras palavras: defrontado com o medo de um invasor desconhecido, com a fragilidade de sua existência, o sujeito projeta em alguns personagens sociais ou situações esse aspecto ameaçador, para lidar com ele mais facilmente, como se este aspecto não fosse parte dele próprio. Ao passo que, para continuar convivendo com seus objetos de amor, faz um processo de formação reativa, extrai deles o perigo, o nojo, convertendo-os em apego e proximidade. Mas a mente é traiçoeira. Denuncia esse mecanismo de defesa utilizado exatamente nessa contradição entre os diferentes padrões de comportamento exercidos. É ai que captamos o núcleo doloroso com o qual ninguém quer de fato lidar: a morte. Trataremos dela, a seguir, com maior profundidade.

\section{A Morte}

Falar de forma científica e acadêmica da morte é tratá-la como objeto externo a nós, em um lugar seguro distante de nós, mesmo que ela seja a única certeza da vida que não pode ser negada. Construímos em torno dela um tabu, na medida em que se impõe, transgredindo todos os limites que a sociedade criou para distanciá-la. Historicamente, retiramos os cemitérios do interior da cidade, os velórios já não são 
usualmente feitos nas casas ou igrejas, há ambientes específicos, delimitados para que a morte possa se expressar. Isso nos dá uma ilusória sensação de controle sobre ela. (RODRIGUES, 2006).

Iniciaremos nossa discussão tratando da individualidade, como domínio do "eu” que não quer se perder no "nós" da sociedade. Queremos estar inseridos num grupo, necessitamos desse pertencimento, mas concomitante a isso, valorizamos nossa identidade. Interessante ver esse fenômeno nos tempos de pandemia, em que o uso de máscaras se fez obrigatório. Quando poderíamos usar um acessório simples, buscamos a personalização do mesmo. Expressamos nossa singularidade na forma de nos apresentarmos. Há máscaras de grife, máscaras neutras, máscaras cômicas, etc. Há inclusive quem tenha estoques de máscaras de alta performance, mesmo quando estas estão recomendadas preferencialmente para o uso de profissionais de saúde, ou que lidam diretamente com ambientes de contaminação, dada sua escassez no mercado. Por quê? Simplesmente para evitar essa dissolução do "eu" no "nós" da sociedade e da cultura. Preservamos nossa vida como coletividade, mas também queremos fazê-lo como indivíduos.

A sociedade tenta imprimir sua marca e suas regras em cada um de seus membros, acolhendo-os em seu seio, mas afastando-os de sua singularidade; há nela um apelo pela uniformidade que pode, em algum momento nos incomodar. Em comunidade pensamos no bem estar geral, decidimos coletivamente os rumos que serão seguidos. O paradoxo disso é que quando se está inserido em uma cultura, marcada por leis e ordens, em que haveria suposta segurança para os sujeitos, a ameaça da perda desse controle lhes gera pânico, ao mesmo tempo em que somente a perda dele pode proporcionar genuína liberdade ao individuo. Dai a ameaça devastadora da morte. Como dito, ela ignora as barreiras, penetra a sociedade, mesmo que esta tente aprisioná-la em cemitérios, hospitais e funerárias. Ela é um fantasma constante nos assombrando com nossa fragilidade. Para Louis-Vicent Thomas citado por Rodrigues (2006, 1. 210) "é no momento em que tomo consciência de minha finitude que cada instante de minha vida se carrega de todo o peso do meu destino". Freud (1996, p. 252) fez reflexão análoga ao descrever os estados de luto e melancolia:

Quando, em sua exacerbada autocritica, ele se descreve como mesquinho, egoísta, desonesto, carente de independência, alguém cujo único objetivo tem sido ocultar as fraquezas de sua própria natureza, pode ser, até onde sabemos, que tenha chegado bem perto de se compreender a si mesmo; ficamos imaginando, tão somente, por que um homem precisa adoecer para ter acesso a uma verdade dessa espécie.

Infelizmente, apenas em contato com o que há de mais sensível em nós, fragilidade e finitude, conseguimos expandir nossa compreensão como indivíduos e como parte do mundo que nos cerca. Como constatado acima, é triste que a maioria de nós só consiga vivenciar este estado de clareza quando muito adoecido ou perto do fim.

Tanto no nível individual quanto no coletivo há angustia ligada à morte. Ela traz consigo representações antagônicas de perda da identidade, perda dos controles e limites sociais, mas, sincronicamente, alude à libertação dessas amarras. Isso ameaça as estruturas de poder instituídas socialmente. Talvez esteja ai um dos motivos pelos quais o suicídio seja tão repudiado em nossa cultura; encerra em si uma liberdade para definir a própria finitude que poder nenhum conseguiria controlar (RODRIGUES, 2006, 1. 3848-4148). Mas essa digressão é tema para outra pauta.

A morte do outro atesta nossa própria finitude e precariedade. Dado este fato, justificam-se os esforços solidários para a manutenção da vida de toda a comunidade. É necessário negar essas fragilidades e, para isso, a mente usa todos os recursos disponíveis: medo, racionalização, nojo. Para Freud, citado por Laplanche e Pontalis (2001, p. 294-295) “ao primeiro "não” de recusa vem juntar-se imediatamente uma confirmação, a principio indireta". Discutindo o mecanismo de defesa da negação, comentam que quando 
se contradiz algo, isso não passa de resistência, dando, uma vez mais, razão àquilo que foi negado. Dessa maneira, quanto mais se nega a morte, mais ela se faz presente e requer uma significação.

Não se pode deixar de abordar nessa discussão o fenômeno curioso ocorrido nos tempos em que vivemos: o negacionismo. Assim como na chamada "Revolta da Vacina" ocorrida no Brasil do inicio do século XX, temos grupos que, por questões politicas, ideológicas, ou por simples negação da ciência, se recusam a aderir aos programas de prevenção instituídos, acreditando em ideias conspiratórias, desejando, quase ingenuamente, que as questões sanitárias vividas, bem como os problemas socioeconômicos sejam mitigados e suas vidas retomem o curso anterior. Tratar-se-ia, portanto, de uma manifestação de pensamento mágico, que impede os sujeitos nesse estado de compreenderem sua condição e aprender, se aprimorar com a experiência.

Uso o termo pensamento mágico para designar o pensamento que se apoia numa fantasia de onipotência para criar uma realidade psíquica que o indivíduo vivencia como "mais real" do que a realidade externa - por exemplo, como pode ser observado no uso de defesas maníacas. Esse pensamento substitui a realidade externa atual por uma realidade inventada, mantendo assim a estrutura existente do mundo interno. Além do mais, subverte a oportunidade de aprender a partir das experiências de vida com objetivos externos reais. O preço psíquico pago pelo individuo em razão da crença no pensamento mágico é pratico: o pensamento mágico não funciona, pois nada pode ser construído sobre ele a não ser outras camadas de construções mágicas. (OGDEN, 2012, p. 194)

Quando se nega a doença, o sujeito se recusa a entrar em contato com sua própria possibilidade de convalescença ou morte. O pensamento mágico entra em cena construindo um palco onde uma vida irreal será teatralizada, uma vida em que a doença não existe, ou que a finitude não está batendo em nossas portas. O nojo tem enfraquecida sua força delimitadora quando grupos ignoram o patógeno. Magicamente as fantasias onipotentes e maníacas assumem o leme dessa nau de negacionistas. Eles sequer notam que, por detrás das cortinas deste teatro, a negação que sustentam reafirma o elemento negado: o adoecer e o morrer. Estes são constantemente ressignificados por rituais que darão nova roupagem a angústias fundamentais de todo ser vivente.

Podemos notar como essa necessidade é presente em nossa cultura, ao observarmos os ritos fúnebres, a forma de sepultamento e as lápides. Rodrigues (2006, 1. 4264) observa que o mundo dos mortos institui-se como representação simbólica do mundo dos vivos e de seu universo social. Toda essa cerimônia é justamente para encenar uma negação daquilo com o que não queremos lidar: o corpo morto e as fragilidades a que ele alude. A essa continuidade que damos ao morto, não deixando que ele desapareça, simbolicamente negamos a morte, mas de modo simultâneo, confinamos este elemento em local seguro, para que sua existência não comprometa o ambiente dos vivos. Envolvida em camadas de continentes (túmulos, caixões, mortalhas, roupas), essa alegoria desempenha sua função de ritualizar o conteúdo que se nega.

Não é a própria fossa, mas sua vacuidade, sua insignificância, seu silencio, sua escuridão... O objeto funerário assinala o não-vazio: ele semantiza o absurdo, conta o após-morte, faz da morte uma segunda existência... Por esta relação imaginária entre o visível e o invisível, o significante e o significado, o objeto se transcende, tudo se semantiza - o objeto e a morte. (URBAIN citado por RODRIGUES, 2006, 1. 4264).

Existe a necessidade de se nomear as emoções. Toda forte angústia que não é conhecida, ou reconhecida, pelos homens se torna um terror sem nome, que não sendo devidamente nomeada ou compreendida será atuada. É o que se chama em psicanálise de acting out (atuação; ações marcadas por impulsividade, 
que rompem com o sistema usual de motivações do individuo). A vacuidade citada acima remete ao vazio interior de cada ser humano e à maneira como nós elaboramos isso. Como compreendemos e significamos a vida e a morte nos ajudará a lidar com o fenômeno da pós-morte. Semantizar, dar sentido à angustia da finitude e da não existência nos impõe a necessidade de atuar. O objeto funerário é continente não só para o corpo morto em si, mas a toda a esperança depositada no vir a ser daquele sujeito que se vai. O morto é um conteúdo a ser elaborado, ressignificado para encontrar seu lugar de descanso no interior da mente de cada membro da sua comunidade. Para que todos estes não tenham que exercer essa função de continente, criam-se rituais fúnebres, homenagens, sepultamentos elaborados, urnas decoradas e toda sorte de símbolos que façam por nós a tarefa de dar sentido a esse silêncio.

O crescente número de casos fatais ligados direta ou indiretamente à pandemia de COVID-19 tem causado colapso dos sistemas hospitalar e funerário em varias partes do mundo. O que se vê é uma população aterrorizada, consternada, e muitas vezes enojada, pela cena trágica de não ter a possibilidade de significar e sepultar adequadamente seus mortos. Seguem-se cenas aterradoras de famílias desorientadas por verem seus entes sepultados em valas comuns, pessoas lutando para ter uma lápide para a qual prestarão suas homenagens, ou ainda episódios dantescos, em que parentes abrem urnas funerárias para ter certeza que estão sepultando seus familiares, não os de outrem. É o exemplo claro de acting out, nenhum deles está em condições emocionais de lidar com o silêncio psíquico da perda, com o vazio da morte. São impulsionados por uma onda emocional que busca garantir a segunda existência do ente que parte, a vida do ente que fica, o significado simbólico da humanidade e da vida em sociedade. Perdido este norte, seremos selvagens. É contra essa intrusão do natural profano que se luta. Noticias falsas de sepultamentos de caixões vazios invadem a internet, há medo e horror, o tal terror sem nome está em cena, com todo o protagonismo imaginável.

Poderíamos discorrer páginas e páginas de eventos atípicos ligados a este período. O que importa aqui salientar é como tudo isso corrobora com o exposto: a morte é tabu, temos medo de que ela nos invada, nos domine. Quando conferimos se há o corpo no caixão, estamos tendo certeza dessa demarcação entre os vivos e os que se foram. Celebrando a morte, guardamos as angústias a ela relativas num lugar seguro, longe de nós. Ao homenagear os falecidos com belos epitáfios, homenageamos os mortos, para além da morte, em sua continuidade no imaginário social. Mas, acima de tudo, cada epitáfio é também uma celebração da continuidade dos que ficam.

Essa dialética entre vida e morte, o aqui e o além, será pano de fundo para que, no intimo de cada ser humano se trave uma batalha entre suas energias pulsionais de vida e de morte. Entendemos como pulsão de vida a energia voltada para a autoconservação, enquanto a pulsão de morte tende à redução das tensões, reconduzindo o ser vivo a um estado "anorgânico" (LAPLANCHE E PONTALIS, 2001, p. 407). Isto seria, em outros termos, um embate íntimo entre duas grandezas. Por um lado há toda a energia que motiva a manutenção da unidade e existência, não só como organismo vivo, mas como ser singular, pensante e ativo. Por outro se vê a tendência à redução completa das tensões, arrastando o individuo a uma paralisia que o aniquilaria. Direcionada para o mundo externo, a pulsão de morte assume ares de agressividade e destruição. O equilíbrio dinâmico dessas duas energias garante, em ultima instância, que indivíduos, sociedade e natureza continuem a existir, perseverando apesar dos conflitos e contradições.

\section{Considerações finais}

Como visto, nojo e morte entrelaçam-se para compor as barreiras e limites sociais. O nojo nos protege contra os perigos insidiosos que a doença pode trazer, aproximando-nos indesejavelmente da morte, 
que carrega consigo a ameaça da liberdade, assim como da desestruturação social. Para Rodrigues (2006, 1. 2057) "as praticas higiênicas imunizam mais as ideias que as coisas; os micro-organismos patogênicos ameaçam mais a vida social que a vida orgânica, e por isso são objeto de ritos purificatórios”. A purificação é nossa forma simbólica de eliminar o indesejável da mente, fazendo um movimento de reparação na estrutura social. Quando muitos adoecem ou morrem, há uma quebra de padrões, tudo se desorganiza. Somos forçados a pensar mais ativamente em questões com as quais não temos contato constante. Somos colocados diante da quebra de tudo que críamos ser perene. "A assepsia corporal é também uma profilaxia simbólica" (RODRIGUES, 2006, 1. 2055). Essas práticas traduzem para a linguagem do corpo alguns conteúdos que são para além dele, são da ordem do simbólico.

Tudo que temos para nos sustentar enquanto comunidade é nosso tecido social. Quando ele se rasga, em decorrência de eventos traumáticos, ficamos "nus", desamparados diante de um mundo hostil e assustador. Essa cena é um banquete para que nossa faceta inconsciente mais desajustada apareça. Lidamos atualmente com sintomas emocionais, em grande parte, decorrentes dessa quebra de paradigmas. Em todos os tempos, por critérios subjetivos ou sociais, definimos com quem compartilharíamos nossa intimidade física e psíquica. Com as novas exigências, vindas de uma ordem médica e das autoridades politicas, ritualizadas em suas formas de expressão e manutenção da ordem social e da estrutura de poder, temos nossos relacionamentos revirados. O que antes era ignorado ou desprezado, agora emana nojo, repulsa ou até mesmo horror. Mas não nos deixemos iludir. Não é o critério sanitário ou higienista que define essas questões, mas sim as estruturas tabus da sociedade. Continuamos a escolher determinados grupos com quem vamos confraternizar, compartilhar fluidos corporais, talheres, roupas, bem como aqueles a quem repudiaremos com tamanha veemência que até assustaria o observador menos atendo a essa dinâmica.

A vida de antes não pode ser resgatada. O mundo jamais será o mesmo, assim como também não o foi depois da peste negra, varíola ou gripe espanhola. Rupturas tão intensas no tecido social causam cicatrizes, registros de memória que modificarão a geração que as vivenciam e as ulteriores. As crises econômicas, politicas e sociais não podem ser negadas, não há mecanismo de defesa do ego que impeça esse processo. Mesmo os sujeitos em franca psicose, não estando em plena consciência do real, serão marcados por tais cenários. O pensamento mágico é incapaz de voltar o tempo. Recusar-se a lidar com as consequências presentes na crise trazida pelo COVID-19 é sobrepor camadas e camadas de pensamento disfuncional e pouco realista.

\section{Referências}

CHALLOUB, Sidney. Cidade Febril: cortiços e epidemias na Corte imperial. Companhia das letras: São Paulo, 1996.

FREUD, Sigmund. Notas sobre um caso de neurose obsessiva (1909). In: Obras psicológicas completas de Sigmund Freud. Vol. X. Rio de Janeiro: Imago, 1996.

FREUD, Sigmund. Obras psicológicas completas de Sigmund Freud: edição standard brasileira. Vol. $X$. Notas psicanalíticas sobre um relato autobiográfico de um caso de paranoia (dementia paranoides) (1911). Rio de Janeiro: Imago, 1996.

FREUD, Sigmund. Obras psicológicas completas de Sigmund Freud: edição standard brasileira. Vol. XIV. A história do movimento psicanalítico, artigos sobre a metapsicologia e outros trabalhos (19141916). Rio de Janeiro: Imago, 1996.

OGDEN, Thomas H. Sobre três formas de pensar: o pensamento mágico, o pensamento onírico e o 
pensamento transformativo. Revista Brasileira de Psicanálise - vol. 46, n 2, p. 193 a 214, 2012. OMS - Organização Mundial da Saúde. COVID-19: cronograma da ação da OMS. Disponível em < https://www.who.int/es/news-room/detail/27-04-2020-who-timeline---covid-19> acessado em 30/04/2020.

RODRIGUES, Jose Carlos. Tabu da morte [Livro eletrônico]. Rio de Janeiro: Ed. FIOCRUZ, 2006.

RODRIGUES, Jose Carlos. Tabu do corpo [Livro eletrônico]. Rio de Janeiro: Ed. FIOCRUZ, 2006.

SANTOS, Boaventura de Sousa. Vírus: tudo que é sólido desmancha no ar. In TOSTES, A. MELO FILHO, H. Quarentena: reflexões sobre a pandemia e depois. Recurso digital, 1.ed. Bauru: Canal 6, 2020.

Artigo recebido em: 31 de maio de 2020

Artigo aceito em: 17 de junho de 2020 